ren weltgeschichtlich nicht erfolgreich. Beispiel: der Mithras-Kult. Dass un- oder halblautere Mittel ein privilegiertes Instrument der Durchsetzung von Minderheiteninteressen sind, ist ebenfalls nichts Neues. Beispiele: das Christentum und der Mithras-Kult - wie auch all die anderen institutionalisierten Religionen. Dass immer jemand auf der Strecke bleibt, mag man bedauern, ist aber kein Phänomen der Dekadenz, sondern unterschiedlicher Ausprägungen des Willens zur Macht. Um sich selbst, ist man in der Auseinandersetzung unterlegen, nicht das Leben zur Hölle zu machen, scheint es eher ratsam, sich einen Habitus gelassener Verachtung zuzulegen - für Immobilienhaie und Grenzüberschreiter jeder Couleur.

Der Analyse stimme ich zu. Auf die Gegenwart übertragen, muß ich freilich feststellen, daß wir es sind, die Demokraten alten Schlages, die unterzugehen drohen, wenn wir uns nicht zu mehr als Verachtung aufraffen, um die Demokratie gegen selbstgerecht dekretierende Minderheiten zu verteidigen.

\title{
Die Grenze der Anderen
}

Ein anderer Punkt ist mir wichtiger. Nämlich Dein Einwand, dass meine Idee der Selbstbestimmung weitgehend Fiktion ist, weil wir stets in Interaktion stehen - weil unsere Selbstbestimmung stets bei der Selbstbestimmung der Anderen endet, mögen die nun Immobilienhaie, rechte oder linke Schreihälse oder unsere Freunde, Partner, Kinder sein. Wir haben die Welt - und Du beschreibst es mit Deiner Eigentümergemeinschaft ja drastisch - meist nicht unter Kontrolle. Wie soll Selbstbestimmung möglich sein, wenn die Welt uns ständig daran hindert, unser eigenes Ding durchzuziehen? Die klassische Antwort auf diese Frage gibt der Stoiker Epiktet, dem als Sklave in römischen Diensten wohl schmerzlich bewusst war, was es bedeutet, die Umstände seines Lebens nicht in der Hand zu haben. Er schlug vor, scharf zwischen dem zu unterscheiden, was in unserer Macht liegt, und dem, was es nicht tut. Nicht in unserer Macht liegt nach stoischer Lehre all 
das, was man gewöhnlich für wichtig hält, nämlich Besitz, Ansehen, Wirkung in der Welt, Gesundheit, der eigene Körper. In unserer Macht steht nach Epiktet hingegen unser Innenleben, unsere innere Vortrefflichkeit, alles, was einst auf Deutsch «Tugend» hiess. Das Wort Tugend klingt für heutige Ohren moralinsauer, gewährte einst aber weitreichende Lizenzen. "Und das, was in unserer Macht steht, ist seiner Natur nach frei, nicht zu hindern, nicht zu hemmen; was aber nicht in unserer Macht steht, ist ohnmächtig, sklavisch, behindert, fremder Verfügung unterworfen.» McCauley in "Heat» hat offensichtlich sei-

58 nen Epiktet gelesen, wenn er seinen Protagonisten vor jeder Bindung an Menschen, weltliche Güter oder moralische Positionen innerhalb von 30 Sekunden Reissaus nehmen lässt.

Mit der richtigen stoischen Einstellung läßt sich anscheinend auch Raub und Mord legitimieren. Dein McCauley ist ja nicht einfach ein liebenswerter Gauner, sondern geht über Leichen, wenn es sein muß. Die alten Stoiker hätten diesen banditischen Immoralismus sicher nicht gebilligt.

\section{Auf dem Grill der eigenen Weltanschauung}

Mich interessiert an ihnen weniger die Moral als vielmehr das Selbstbezwingungsvermögen. Seneca malt drastisch aus, wie grosse Weise äusserste Qualen erlitten haben und dennoch standhaft geblieben sind. Ein derart Standhafter würde, wenn man ihn im Bronzestier des Tyrannen Phalaris auf kleinem Feuer langsam röstet, noch ausrufen: «Wie süss ist das doch, und der Schmerz geht mich nichts an!» Der Weise erträgt mannhaft jede Tortur und wird daran nicht irre.

Du willst uns doch nicht etwa jetzt ein Leben empfehlen, bei dem man im Zweifelsfall als Bratling auf dem Rost endet? Immerhin preist Du gerade Haltungsfanatiker, von denen Du Dich bislang distanziert hast. 